\title{
Congenital cystic adenomatoid malformation, antenatal diagnosis: about one case
}

\author{
Dembélé Adama $^{1 *}$, Ouédraogo Issa ${ }^{2}$, Kiemtoré Sibraogo $^{3}$, Bambara Moussa $^{1}$
}

\begin{abstract}
${ }^{1}$ Department of Obstetrics, Gynecology and Reproductive Medicine, Souro Sanou Teaching University Hospital, Bobo Dioulasso, Burkina Faso

${ }^{2}$ Departement of Obstetrics and Gynecology, Training and Research Unit in Health Sciences, Ouahigouya University, Burkina Faso

${ }^{3}$ Departement of Obstetrics and Gynecology, Training and Research Unit in Health Sciences, Professor Joseph Ki Zerbo University Ouaga, Ouagadougou, Burkina Faso
\end{abstract}

Received: 12 January 2019

Accepted: 09 May 2019

\section{*Correspondence:}

Dr. Dembélé Adama,

E-mail: dembadama@hotmail.fr

Copyright: (c) the author(s), publisher and licensee Medip Academy. This is an open-access article distributed under the terms of the Creative Commons Attribution Non-Commercial License, which permits unrestricted non-commercial use, distribution, and reproduction in any medium, provided the original work is properly cited.

\begin{abstract}
Antenatal ultrasound screening of fetal malformations requires for management, the immediate nature of which at certain birth, conditions the survival of the newborn. The Objectives Describe a case of pulmonary cystic adenomatoid malformation discover during antenatal ultrasonography. It was a 36 years old primary patient, referred to the maternity of Lafontaine hospital (France) for the presence, on obstetrical ultrasound screening, of suspected lesions on the foetal right lung's field in a 21 weeks gestation pregnancy. After successive obstetric ultrasound scan, it was discovered that the left lungs were big with some parenchymal cysts of different sizes more than $3 \mathrm{~mm}$ in diameter. We made a diagnosis of type I left pulmonary cyst adenoma with excess amniotic fluid, without associated anomalies. The pregnancy progressed to 40 weeks gestation and a caesarean section was done with extraction of a live female new born weighing 2730 gr. The new born had 40 days later a successful surgical lobectomy for a cystic adenomatoid dysplasia. Histological examination revealed type I Stocker congenital pulmonary cystic adenomatoid malformation. During obstetrical ultrasound screening, we paid more attention to the brain, the heart, the face. Through this study we realised that during routine antenatal ultrasound for morphology, we should also pay more attention to the lungs.
\end{abstract}

Keywords: Antenatal ultrasound screening, Congenital cystic adenomatoid malformation, Post natal lobectomy

\section{INTRODUCTION}

Pulmonary cystic adenomatoid malformation (PCAM) or pulmonary adenomatous cyst malformation (PACM) or congenital pulmonary cystic adenomatoid malformation (CPCAM) or Craig disease is pathology of lungs dysplasia following an arrest in the development of normal bronchioles by bronchiolar atresia, possibly of vascular origin. ${ }^{1}$ It antenatal diagnosis can be done from 16 weeks gestation. A surgical excision in the corresponding lobe after delivery is safer for the new born. This justifies the ultrasonography place in the diagnosis and antenatal follow up of foetal malformations in view of providing post natal treatment of the pathology. ${ }^{2}$

We present a case of pulmonary cystic adenomatoid malformation observed in obstetric and gynaecological ultrasound scan unit of "La Fontaine General Hospital Centre" in Saint-Denis (France). Through this study, we describe the ultra sound scan diagnostic elements and steps that brought to the therapeutic treatment of the new 
born. A discussion from review of literature will conclude our work.

\section{CASE REPORT}

\section{Patient's characteristics}

A 36 years old married woman, from North African, primigravida, with no particular past family history. Blood group $\mathrm{O}$ rhesus positive with body mass index of 24, 7(148/54). Neither known hypertensive nor diabetic. Immune against rubella, serology of syphilis and toxoplasmosis negative. She has never been transfused, had tonsillectomy and hernia repaired without any problem. The present pregnancy is not induced and has not presented any problem clinically.

\section{Antenatal diagnosis}

She was received in the obstetric ultrasound scan unit of the maternity for the presence of foetal multi-cystic lesions of few centimetres and 4 in number with some confluent and all located in the right hemi-thorax. This aspect could be suggesting cystic adenomatoid malformation on a pregnancy of 21 weeks +5 days amenorrhea. An ultrasound scan monitoring pregnancy was done to determine this foetal lungs malformation. Three ultrasound scan where done, at 23 weeks, 24 weeks, and 27 weeks +4 days amenorrhea. The last ultrasound scan provided the diagnosis:

\section{Left lung}

Large with cysts of different size up to $3 \mathrm{~mm}$ in number of three or four, hyperechoic. The left lung pushes the heart to the right.

\section{Right lung}

Normal with a volume of $2.5 \mathrm{~cm} 3$.

\section{Foetal position}

Extended breach, head in the right corn, active foetal movement, cardiac activities++.

\section{Biophysical profile normal}

BPD: $71 \mathrm{~mm}$, corresponding to 75 th percentile, HC: 259mm $>50$ th percentile, ATD: $76 \mathrm{~mm}>90$ th percentile, AC: $246 \mathrm{~mm}<75$ th percentile. FL: $52.5 \mathrm{~mm}=50$ th percentile, hearth circumference/thoracic circumference: $91 / 218=0.42$.

\section{Cephalic structures normal}

Following structure seen. HC, lateral ventricles, cerebral peduncles, thalamus, septum pellucidum. The cerebellum measure $31 \mathrm{~mm}$ over $16 \mathrm{~mm}$.
Face normal: orbit cavities, nose and the mouth were visualised.

\section{Cervical structure seen}

vertebral column, anterior and posterior column.

\section{Thorax hearth and vessel normal}

Following structure visualised 4 cavities, inter-ventricular septum, inter-auricular septum, foramen ovale, vieussens valve, mitral valve, tricuspid valve, great vessels, and aortic arch descending aorta, inferior vena cava, and normal basal rhythm. At the level of the abdomen are seen the following: diaphragmatic domes, liver, gall bladder, stomach, right and left kidneys, urinary bladder. Abdominal wall seen in it width, Genital organs: XX. Skeleton: the dorso- lumbo- sacral spine is visualized. At the level of the 2 upper limb: arms, forearms, hands were seen. At the level of the 2 lower limbs: thigh legs and foots.

\section{Adnexa}

The placenta was located posteriorly, normal inserted, grade I and of normal width, the umbilical cord has a velamentous insertion in the fundus of the uterus with 3 vessels.

There was a frank excess of amniotic fluid and the umbilical arterial Doppler ultrasound scan was normal with a resistance indices of 0.65 .

\section{Ultrasound scan diagnostic: left lung adenomatoid type I - Excess amniotic fluid.}

\section{Practical conduct}

Ultrasoun scan diagnosis of type I adenomatous left lung disease with excess amniotic fluid. No foetal malformation was observed was found during different examinations.

The patient continue her ante natal follow up In Robert Debre Hospital and delivered by caesarean section after 40 weeks and 2 days amenorrhea of a new born female of 2730 grams, Apgar score of 9/10, indication for caesarean section was: breach presentation with generally retracted pelvis.

The new born was operated 42 days later in the visceral surgical department of the same Hospital. The indication was: left inferior lobe adenomatous dysplasia of the lung. At the opening of the pleura, a voluminous adenomatous dysplasia of the inferior left lobe of the lung was noted with a ream of healthy parenchyma. Left inferior lobectomy was done. Histology confirmed the diagnosis. In Stocker classification, it was type I, and post operatively the new born was doing well. 


\section{DISCUSSION}

PCAM represent $21 \%$ of foetal malformation and $71 \%$ of pulmonary malformations. ${ }^{3}$ Many studies have already been done on PCAM. With many important differences more importantly on gestational age at the discovery of the pathology, circumstances of the discovery, relationship between foetal sex and the malformation, the type in the histological and USS classification, unique or bilateral pulmonary location, prognosis of the outcome of the pregnancy, associated malformations, type of management, and so on. Our discussion will be on those different elements.

\section{Antenatal period findings}

It is known classically that the diagnosis of PCAM is during the $22^{\text {nd }}$ weeks amenorrhea. ${ }^{3}$ That gestational age varies according researches. Taguchi et all made antenatal diagnosis at 24th weeks amenorrhea. ${ }^{4}$ Entezami did antenatal diagnosis at 23rd weeks. ${ }^{5}$ In our study, antenatal diagnosis was done at 21 weeks +5 days. Operator's experience matters in the accuracy early diagnosis. Early antenatal diagnosis (before 19th weeks) has no direct influence on the progress of the pregnancy but mostly link with associated malformations. ${ }^{3}$

\section{Pulmonary location and ultrasound type of PCAM}

Studies done shows unilateral pulmonary location. In one retrospective study, Sapin and collaborators found in a period of 10 years, 18 cases of antenatal diagnosis of PCAM; 17 cases were unilaterally located (13 to the left and 4 to the right), only one case has bilateral location. ${ }^{6}$ Cha in a study of 11 cases of PCAM found 10 cases had unilateral left lung location and uni-lobar. ${ }^{7} \mathrm{We}$ have found in our observation a case of PCAM located in the left lung. In fact the prognosis of PCAM does not depend on the right or left location of the lesions. Bilateral location has a reserved prognosis.

Stocker classification is a histological classification base on the size of the cysts. 3 types or 3 groups are defined in decreasing order. ${ }^{8}$ Adzick proposed an ultrasound scan classification that distinguishes in one side macroscopic type (corresponding to the Stocker type 1and 2) with cysts $\geq 5 \mathrm{~mm}$, and on the other side microscopic type, hyper echogenic (corresponding to Stocker type 3) with cysts $<5 \mathrm{~mm} .{ }^{9}$ Most authors seam to adopt the stocker's classification. ${ }^{8}$ Between the two extreme 1 and 3 there are many intermediaries. ${ }^{1}$ Belkheiri $M$, found type 1 histologically. ${ }^{10}$ Jamet found type 2.11 Our study found type 1 .

\section{Evolution and associated malformations in PCAM}

It is better to distinguish associated PCAM malformation that form with it a foetal poly-malformation table from the malformations occurring as a result of physiological evolution of PCAM. Adzick and colleagues found that associated malformations are relatively rare in PCAM. ${ }^{9}$ Laberge precise in multicentre study of 40 cases of PCAM that 2 cases were presenting multiple malformations with hydrops and one presenting with severe oligoamnios. ${ }^{3}$ He found that 4 foetuses had important mediastinal deviation. In these cases, he did not emphasise whether it was associated malformation or evolutional malformation. According to our study, evolutional or associated malformation observed depends on the gestational age that the diagnosis was made. In fact, early diagnosis around the 17th week gestation allows diagnosing the isolated character of the PCAM; that is the absence of associated initial malformations. Good monitoring USS will discover the appearance or not of evolutional malformations of which the prognosis depend on.

In our case report, there were no associated malformations. We only observed an excess amniotic fluid without been polyhydramnios. We then join Adzick who emphasized associated malformations were rare

\section{Intra uterine prognosis}

Prognosis justifies the antenatal diagnosis and the place of ultrasound scan in the management of such pregnancy. It is to know the gravity of the condition and to which extend we could go if something should be done or not. Some authors were interested in ultrasound scan signs of PACM, that determine the faith of the pregnancy and the well been of the foetus. The faith of the pregnancy could take different directions base on the ultrasound scan signs: spontaneous regression of the lesions, ${ }^{12}$ intra uterine foetal death, ${ }^{5}$ intra uterine treatment, ${ }^{12}$ eugenic miscarriage, ${ }^{13}$ delivery and immediate management signs describing the diagnostic gravity (foetal ascites, hydramnios and anasarca). ${ }^{1}$ Apart from evolutional and associated malformations, the height of the cyst also modifies the foetal prognosis. Some authors agree on that: macroscopic pulmonary lesions (Stocker type 1) that are diameter $\geq 3 \mathrm{~mm}$ are of good prognosis for the foetus. A microscopic pulmonary lesion (Stocker type 3 ) that is diameter $<3 \mathrm{~mm}$ are of poor prognosis for the foetus. ${ }^{8}$ Bunduki has then defined some prognostic factors: microscopic lesions, bilateral lesions, foetal ascites, acute hydramnios, mediastinal deviation, are elements of poor prognosis for foetal well been. ${ }^{14}$ Our study found macroscopic pulmonary lesions (Stocker type1).

\section{Delivery method}

Most authors preferred vaginal delivery. Belkheiri reports that the vaginal delivery has been successfully conducted in their study. ${ }^{10}$ Vergnes emphasized that apart from obstetric difficulties, vaginal delivery is preferred. ${ }^{15}$ No criteria define the outcome of the pregnancy. Cases of eugenic miscarriage have been reported and Laberge found $15 \%(7 / 48)$ in his series with $2 \%$ of spontaneous miscarriage. ${ }^{3}$ Monni found $35 \%(9 / 26) .{ }^{13}$ In our study, the delivery method was by caesarean section, obstetric 
indication was breach presentation on a generally retracted pelvis with no relationship with the antenatal diagnosed pathology.

\section{Post-natal treatment:}

Most authors adopt immediate post natal treatment. Therapeutic attitude extend from simple re-education to surgical lobectomy through intubation. Monni affirm that in her series of 26 cases 9 had post natal pulmonary surgery. ${ }^{13}$ Golaszewski emphasized that post natal management was thoracotomy with lobectomy. ${ }^{16}$ Adzick talk of complementarity between thoracocenthesis, intra uterine thoraco-amniotic derivation and post natal lobar resection. ${ }^{9}$ In our observation the new bon was operated 42 days later after birth.

\section{Ultrasound scan and histology correlation:}

The correlation between ultrasound scan images and histology has its importance radiologist. In other words, was the USS diagnosis correct, was necessary to mobilise all this therapeutic chain just for what the sonographer has discovers, is the predictive value of the USS significant in these situations. It is better to remain modest. It is important to note that the first classification of PACM was by USS by stocker in 1977 and was distinguishing 3 types Stocker. ${ }^{8}$ Less than 10 years i.e. 1985 Adzick proposed more concrete antenatal USS classification that distinguished 2 types: macro cystic $(\geq 5$ $\mathrm{mm})$ and micro cystic $(<5 \mathrm{~mm}) .{ }^{17}$

In 1994 Stocker proposed another classification based on histopathology according to the pulmonary epithelial quality. The problem remains the correlation between the USS type and the precised histology type. Some authors admit that USS images cannot be used to determine what will be the precised result of the histology for they could be a regression after the USS diagnosis. ${ }^{1}$ In our observation, USS diagnosis was that of left lung malformation, macro cystic according to Adzick and the histology type 1 Stocker.

\section{CONCLUSION}

At the end of the probe, the sonographer's hands will lead him to make a diagnosis that will mobilize several structures. It's important to know what you're talking about without exaggerating anything. That is the beautiful artistic side of USS especially for the antenatal diagnosis.

In USS unit of the department of obstetrics and gynaecology of the Lafontaine Maternity Hospital in Saint Denis, we make in antenatal an USS diagnosis of PACM of the left lung at 23 weeks amenorrhea. The steps taken for the management was simple with a caesarean section during delivery and post-natal lobectomy. The usefulness of the accuracy of the ultrasound diagnosis was no doubt in this case.
Funding: No funding sources Conflict of interest: None declared

Ethical approval: Not required

\section{REFERENCES}

1. Marie Carmen DE Frutos. Antenatal ultrasound diagnosis of cystic adenomatoid malformation of the lungs: about two observations at the hospital Notre dame de Bon secours in Paris. Memory. University René Descartes Paris V. 1987;40:5-8.

2. Revillon $\mathrm{Y}$, Jan $\mathrm{D}$, Plattner V, Sonigo $\mathrm{P}$, Dommergues M, Mandelbrot L, et al. Congenital cystic adenomatoid malformation of the lung: prenatal management and prognosis. J Pediatr Surg. 1993;28(8):1009-11.

3. Laberge JM, Flageole H, Pugash D, Khalife S, Blair $\mathrm{G}$, Filiatrault D, et al. Outcome of the prenatally diagnosed congenital cystic adenomatoid lung malformation: a Canadian experience. Fetal Diagn Ther. 2001;16(3):178-86.

4. Taguchi M, Shimizu K, Ozaki Y, Kubota T, Aso T. Prenatal diagnosis of congenital cystic adenomatoid malformation of the lung. Fetal Diagn Ther. 1993;8(2):114-8.

5. Entezami M, Halis G, Waldschmidt J, Opri F, Runkel S. Congenital cystic adenomatoid malformation of the lung and fetal hydrops, a case with favorable outcome. Eur J Obstet Reprod Biol. 1998;79(1):99-101.

6. Sapin E, Lejeune V, Barbet JP, Carricaburu E, Lewin F, Baron JM. Congenital adenomatoid disease of the lung : prenatal diagnosis and perinatal management. Pediatr Surg Int. 1997;12(2-3):126-9.

7. Cha I, Adzick NS, Harrison MR, Finkbeiner WE. Fetal congenital cystic adenomatoid malformations of the lung. a clinicopathological study of eleven cases. Am J Surg Pathol. 1997;21(5):537-44.

8. Stocker JT, Madewell JE, Drake RM. Congenital cystic adenomatoid malformation of the lung: Classification and morphologic spectrum. Hum Pathol 1977;8(2):155-71.

9. Adzick NS, Harrison MR, Crombleholme TM, Flake AW, Howell LJ. Fetal lung lesions; management and outcome. Am J Obstet Gynecol 1998;179(4);884-9.

10. Belkheiri M, Elidrissi F, Bouslami T, Chaoui A. Congenital cystic adenomatoid malformation of the lung. Prenatal diagnosis in a case. Rev Pneumol Clinic. 2001;57(5):356-60.

11. Jamet F, Deschamps F, Giacalone PL, Sarda P, Boulot P.Congenital adenomatoid cystic formation of the lung and renal polycystocis. A fetal case report and review of the literature. J Gynecol Obstet Biol Reprod (Paris). 1997;26(2):193-6.

12. Dommergues M, Louis-Sylvestre C, Mandelbrot L, Aubry MC, Revillon Y, Jarreau PH, et al. Congenital adenomatoid malformation of the lung: when is active fetal therapy indicated. Am J Obstet Gynecol. 1997;177(4):953-8. 
13. Monni G, Paladini D, Ibba RM, Teodoro A, Zoppi MA, Lamberti A, et al. Prenatal Ultrasound diagnosis of congenital cystic adenomatoid malformation of the lung: a report of 26 cases and review of the literature. Ultrasound Obstet Gynecol. 2000; 16(2):159-62.

14. Bunduki V, Ruano R, Da Silva MM, Miguelez J, Miyadahira S, Maksound JG, et al. Pronostic factors associated with congenital cystic adenomatoid malformation of the lung. Prenat Diagn. 2000;20(6):459-64.

15. Vergnes P, Chateil JF, Boissinot F, Galperine RI, Demarquez JL, Vital C, et al. Antenatal diagnosis of lung malformations. A propos of 9 cases reports. Chir Pediatric. 1989;30(4):185-92.

16. Golaszewski T, Bettelheim D, Eppel W, Deutnger J, Bernaschek G. Cystic adenomatoid malformation of the lung: prenatal diagnosis, prognostic factors and fetal outcome. Gynecol Obstet Invest. 1998;46(4): 241-6.

17. Adzick NS, Harrison MR, Glick PL, Globus MS, Andreson RL, Callen PW, et al. Fetal cystic adenomatoid malformation: prenatal diagnosis and natural history. J Pediatr Surg. 1985;20(5):483-8.

Cite this article as: Adama D, Issa O, Sibraogo K, Moussa B. Congenital cystic adenomatoid malformation, antenatal diagnosis: about one case. Int J Reprod Contracept Obstet Gynecol 2019;8:2901-5. 